\title{
Research on the Measurement of Enterprise Technological Innovation Capability Model based on Information Axiom
}

\author{
Huaping Zhang \\ Management and Economics School of North China University of Water Resources \\ and Electric Power \\ zhanghuaping@ncwu.edu.cn

\begin{abstract}
\end{abstract}
Enterprise technological innovation is featured by multi-letel, multitindex, complex with uncertain information. This paper studies the measurement of enterphse technological innovation capability based on measurement index system that can reflect the innovation ability in an objective and systematic way. This index system is constructed according to certain rules and standards and sheds light on the measurement index model based on Euclidean distance and Information axiom. In this model, measurement indicators of different types are standardized and Euclidean distance is established. Then the weight of information content produced by Euclidean distance is calculdted (to) get the comprehensive information content so as to measure the entexprise technologioal innovation capability. Measurement of three enterprises proves the model to be systematic, scientific and feasible.

Keywords: Enterprise technological innovation; Capability measurement; Information axiom; Euclidean distance $\cdot$ Model

\section{Introduction}

In the era of knowledge-based economy, with the development of science and technology and the rising market competition, enterprise technological innovation has become the driven force of the sustainable development as well as the core factor of competition. Therefore, it is necessary to increase the enterprise's innovation capability to be more competitive in the market [1-4].

Currently, many researchers, home and abroad, have studies the measurement of enterprise technologican innovation with fruitful progress [5-9]. However, there is a lack of consensus on measurementanalysis principles, the construction of measurement index system, analysis method and the selection of model. So it is hard to reflect the overall quality of the measurement. Some analytical methods and models are not operational or feasible. Thus, this paper ppoposes a measurement model based on information axiom and previous researches.

\section{The Construction of Measurement Analytical Principles and Index System of Enterprise Technological Innovation Capability}

\subsection{Measurement Analytical Principles of Enterprise Technological Innovation Capability}

Measurement analytical principles are the guidance of the index system. Only with scientific principles can the index system be reasonable. Based on previous researches, this paper proposes the following principles. 
(1) Systematic principle: The process of technological innovation is summed as innovation accumulation, $\mathrm{R}$ and $\mathrm{D}$, manufacturing, sales and reaching economic profits. Therefore, the index system should reflect the actual capability of technological innovation in an all-round way. This is a complicated process of system engineering decision analysis.

(2) Scientific principle: Indicators should not overlap each other. The index system should both address relevant problems of measurement and make sure a clear definition and an objective, accurate and fair measurement and analysis result.

(3) Feasibility principle: The measurement indicators should be feasible and practical, which means the data is acquired effectively, simply and conveniently for effective measurement and analysis.

(4) Purpose principle: Measurement indicators should reflect the level of enterprise technological innovation capability and be able to point out the weaknesses in innovation so as to provide reference and guidance for further improvement.

(5) Layer-clear principle: Measurement indicators of each layer should be distinguished from each other and have clear hierarchy and differences to that they are comparable.

(6) Comprehensive principle: Measurement indicators should refledt the technological innovation in an all-round way. The whole and inner connection of different factors that affect the selection of indicators should be guaranteed. Otherwise, indicators may be incomplete.

(7) Quantitative and qualitative principla Some indicators and quantitative indicators while others are qualitative ones. Quantítativa idicators can produce the accurate quantitative description model. Qualitative indicators can produce fuzzy membership or fuzzy interval description. This ensures the effectiveness of the measurement model of enterprise technological innovation capability.

\subsection{The Construction of Measurement Index System of Enterprise Technological Innovation Capability}

According to abovementioned principles and after consulting with relevant experts and data, the measurement index system is shown in Table 1 aimed at the manufacturing and sale process of technological innovation while taking into consideration human resources, money, innovation institution and innovation prospect.

Table 1. Measurement Index System

\begin{tabular}{|c|c|c|c|c|}
\hline System & $\begin{array}{l}\text { First } \\
\text { measurement } \\
\text { index }\end{array}$ & Weight & Second measurement index & Weight \\
\hline \multirow{4}{*}{$\begin{array}{l}\text { Measurement } \\
\text { index system } \\
\text { of enterprise } \\
\text { technological } \\
\text { innovation } C\end{array}$} & \multirow{4}{*}{ capabilit } & \multirow{4}{*}{$W_{1}$} & $\mathrm{R} \& \mathrm{D}$ funds investment ratio $C_{11}$ & $W_{11}$ \\
\hline & & & $\begin{array}{c}\mathrm{R} \& \mathrm{D} \text { proportion of human } \\
\text { resources } C_{12}\end{array}$ & $W_{12}$ \\
\hline & & & Number of patent $C_{13}$ & $W_{13}$ \\
\hline & & & $\mathrm{R} \& \mathrm{D}$ cycle ${ }^{C_{14}}$ & $W_{14}$ \\
\hline
\end{tabular}




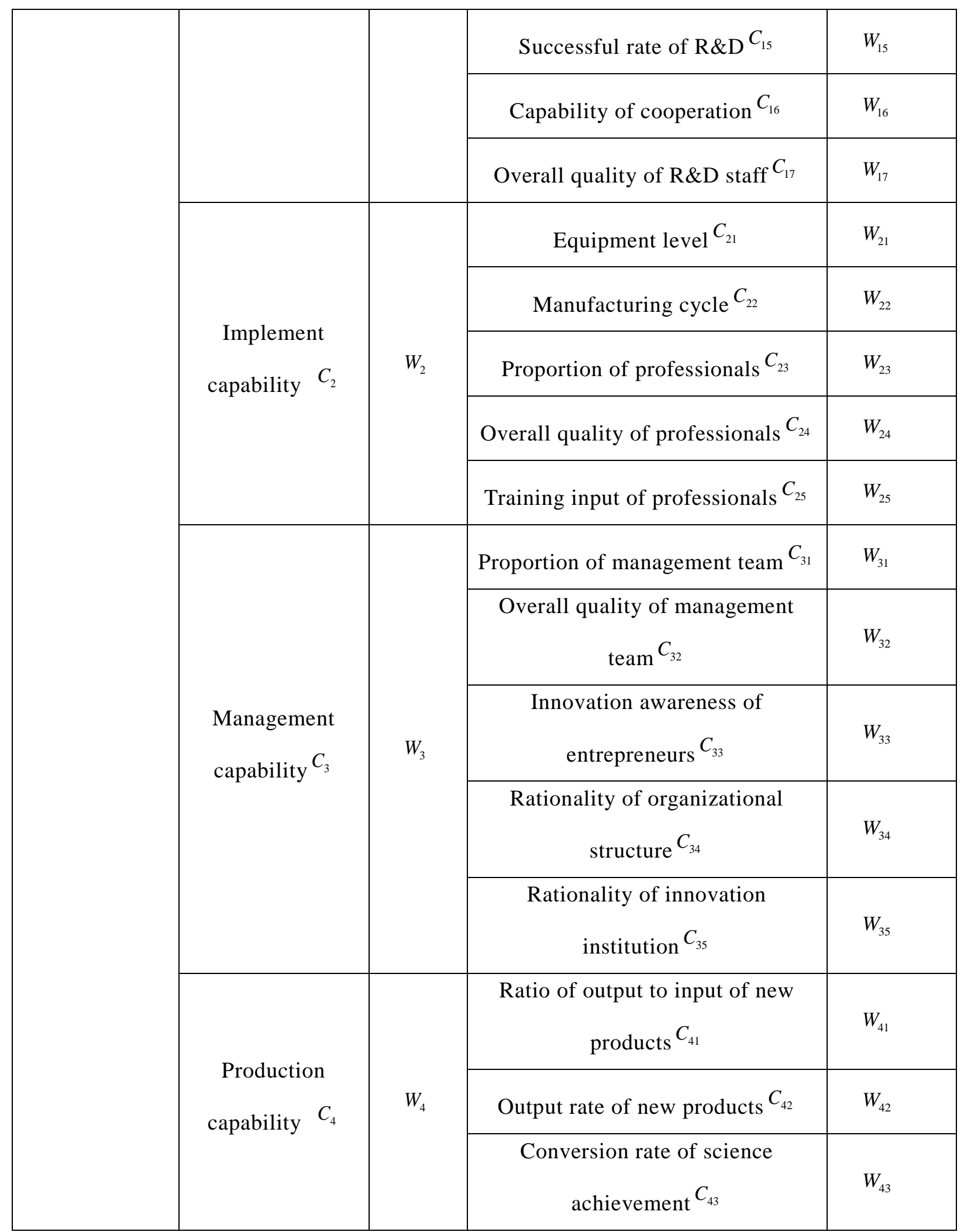




\begin{tabular}{|c|c|c|c|c|}
\hline & \multirow{4}{*}{$\begin{array}{c}\text { Marketing } \\
\text { capability } C_{5}\end{array}$} & \multirow{4}{*}{$W_{5}$} & Market share of new products $C_{51}$ & $W_{51}$ \\
\hline & & & Market research capability $C_{52}$ & $W_{52}$ \\
\hline & & & Marketing cost rate $C_{53}$ & $W_{53}$ \\
\hline & & & Net profit rate $C_{54}$ & $W_{54}$ \\
\hline
\end{tabular}

\section{Measurement Model of Enterprise Technological Innovation Capability based on Information Axiom}

\subsection{Analysis of Information Content Based on Information Axiom}

Axiom design was first introduced by Profeso Suh N P of MIT in 1990. It was the application of Shannon information theory in the field of design as well as an effective decision method [10-13]. Information axiom is an important design theory. It refers to that under the independent axiom, the system the maximum information content $I$ is the best one. Information content $I$ is defined as the logafithmic function of the probability that the system meets the given design,requirement. There is:

$I=-\log _{2} P=\log _{2}(1 / P)$

In the expression, $P$ refers to thexpobability that the system meets the given design requirement.

As the probability function is random, the probability can be expressed as:

$$
P=\int_{b}^{a} p_{s}(D) d D=A_{C}
$$

In the expression, $p_{f}(D)$ refers to the probability distribution function; $a$ refers to the down limit of the design range; $b$ refers to the up limit of the design range; $A_{C}$ refers to the area enclosure by system range and design range.

\subsection{Standardization of Measurement Indicators}

In the measurement index system, some indictors are quantitative indicators while others are qualitative indicators that are fuzzy and uncertain and require fuzzy language for description.

Therefore, in order to effectively analyze the measurement, there is a necessity to standardize indicators of different type. Suppose all the indicators value can be expressed in the form of interval value, that is, $c_{i j}=\left[c_{i j}^{L}, c_{i j}^{R}\right]$. In particular, when $c_{i j}^{L}=c_{i j}^{R}$, $c_{i j}=c_{i j}^{L}=c_{i j}^{R}$ is the accurate information at a point.

Standardization is based on whether measurement indicator $c_{i j}=\left[c_{i j}^{L}, c_{i j}^{R}\right]$ is a positive or adverse indicator. 
(1)When measurement indicator $c_{i j}=\left[c_{i j}^{L}, c_{i j}^{R}\right]$ is a positive indicator, the indicator $v_{i j}$ after standardization is:

$$
v_{i j}=\left[v_{i j}^{L}, v_{i j}^{R}\right] /\left\|C_{i j}\right\|_{\max }
$$

In the expression,

$$
\left\|C_{i j}\right\|_{\max }=\max _{1 \leq j \leq n}\left(\max \left(\left|c_{i j}^{L}\right|,\left|c_{i j}^{R}\right|\right), \max \left(\left|c_{i j}^{L}\right|,\left|c_{i j}^{R}\right|\right), \cdots, \max \left(\left|c_{i j}^{L}\right|,\left|c_{i j}^{R}\right|\right)\right)
$$

It is the maximum norm of design scheme $i$ about measurement indicator

(2)When measurement indicator $c_{i j}=\left[c_{i j}^{L}, c_{i j}^{R}\right]$ is an adverse indicator, the indicator $v_{i j}$ after standardization is:

$v_{i j}=\left\|C_{i j}\right\|_{\min } /\left[v_{i j}^{L}, v_{i j}^{R}\right]$

In the expression,

$$
\left\|C_{i j}\right\|_{\min }=\min _{1 \leq j \leq n}\left(\min \left(\left|c_{i j}^{L}\right|,\left|c_{i j}^{R}\right|\right), \min \left(\left|c_{i j}^{L}\right|,\left|c_{i \unlhd}^{R}\right|\right), \min \left(\left|c_{i j}^{L}\right|,\left|c_{i j}^{R}\right|\right)\right)
$$

It is the minimum norm of desigh scheme $i$ about measurement indicator $j$.

\subsection{Calculation Model of Information Content of Measurement Indicator}

Through the analysis of measurement indicators, it is clear the probability distribution function in whieh different indicators should meet the analysis requirement is not available. So, it is necessary to deal with the indicator value. In this paper, Euclidean distance is introduced for this purpose.

As measurement indicators after standardization have unified scale standard, the optimal measurement indicator sequence $\boldsymbol{V}^{\otimes}$ can be constructed.

$$
\boldsymbol{V}^{\otimes}=\left(\hat{v}_{01}^{\otimes} \underset{v}{v_{02}}, \cdots, v_{0 n}^{\otimes}\right)=\left(\left[v_{01}^{a}, v_{01}^{b}\right],\left[v_{02}^{a}, v_{02}^{b}\right], \cdots,\left[v_{0 n}^{a}, v_{0 n}^{b}\right]\right)
$$

In the expression:

$$
\left.\otimes v_{0 j}^{a}, v_{0 j}^{b}\right]=\left[\max _{1 \leq i \leq m}\left(v_{i j}^{a}\right), \max _{1 \leq i \leq m}\left(v_{i j}^{b}\right)\right]
$$

The Euclidean distance between measurement indicator $j$ and the optimal indicator sequence $\boldsymbol{V}^{\otimes}$ under measurement analysis scheme $i$ is:

$$
D_{\left(v_{i j}, v_{0 j}^{\otimes}\right)}^{i j}=\sqrt{\frac{\left|v_{i j}^{a}-v_{0 j}^{a}\right|^{2}+\left|v_{i j}^{b}-v_{0 j}^{b}\right|^{2}}{2}}
$$


The closeness degree between measurement indicator $j$ and the optimal indicator sequence $\boldsymbol{V}^{\otimes}$ under measurement analysis scheme $i$ is:

$$
\kappa_{\left(v_{i j}, v_{0 j}\right)}^{i j}=1-D_{\left(v_{i j}, v_{0 j}^{\otimes}\right)}^{i j}
$$

The meaning of expression (10) is: If $\kappa_{\left(v_{i j}, v_{0 j}\right)}^{i j}=1$ measurement indicator $j$ and the optimal indicator sequence $\boldsymbol{V}^{\otimes}$ are overlapped; If $\kappa_{\left(v_{i j}, v_{0 j}\right)}^{i j}=0$ measurement jindrcator $j$ and the optimal indicator sequence $\boldsymbol{V}^{\otimes}$ are not overrapped; $100<\kappa_{\left(v_{i j}, v_{0 j}\right)}^{i j}<1$, measurement indicator $j$ and the optimal indicator sequence $\boldsymbol{V}^{\otimes}$ are partially overlapped.

According to statistical distribution, probability that meets the design requirement is expressed by the exponential distribution density function:

$$
P_{i j}=e^{\left.-\mid 1-\kappa_{\left(v_{i j}, v_{0 j}\right.}^{\otimes}\right) \mid}
$$

The information content $I_{i j}$ between measurement indicator $j$ and the optimal indicator sequence $\boldsymbol{V}^{\otimes}$ under measurement analysis scheme $i$ is:

$$
I_{i j}=-\log _{2} P_{i j}=\log _{2} e^{\left.-1-\sum^{i j}\left(v_{i j}\right)_{0}^{\otimes}\right)}
$$

Expression (12) shows that the closer measurement indicator $j$ is to the optimal indicator, the smalter the information content $I_{i j}$ of measurement indicator $j$ will be. Under such circumstance, the measurement analysis scheme is the best one and vice versa.

If the Value of measurement indicator $j$ is acquired, calculate the information content in the same way as addressed above, the information content sequence $I_{i}^{2}$ of measurement indicator $j$ of the second index is:

$$
I_{i}^{2}=\left(I_{i 1}^{2}, I_{i 2}^{2}, \cdots, I_{i n}^{2}\right)
$$

The overall information content $I_{i}^{2}$ of second index under measurement analysis scheme $i$ is: 


$$
I_{i}^{2}=\sum_{j=1}^{n_{s}}\left(W_{i j} \times I_{i j}\right)
$$

the information content sequence $I_{i}^{1}$ of the second index under measurement analysis scheme $i$ is:

$$
I_{i}^{1}=\left(I_{i 1}^{1}, I_{i 2}^{1}, \cdots, I_{i n}^{1}\right)
$$

The overall information content $I_{i}$ of the second index under measurement analysis scheme $i$ is:

$$
I_{i}=\sum_{j=1}^{n_{k}}\left(W_{j} \times I_{i j}^{1}\right)
$$

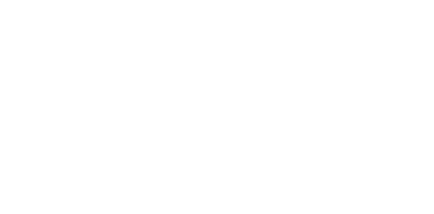

The information sequence $I$ of all measurenent analysis scheme $i$ is:

$$
I=\left(I_{1}, I_{2}, \cdots, I_{m}\right)
$$

According to the optimal principle based on information axiom, if

$$
I_{i}=\min \left(I_{1}, I_{2}, \cdots, I_{m}\right)
$$

Then the measurementanalysis sobeme $l$ is the optimal measurement scheme which means this scheme has the best technplogical innovation capability.

\section{Case Study and Model Test}

\begin{tabular}{|c|c|c|c|c|c|c|}
\hline \multirow{3}{*}{$\begin{array}{c}\text { First } \\
\text { measurement } \\
\text { index }\end{array}$} & & $\mathrm{Ca}$ & ility & & & \\
\hline & \multirow[b]{2}{*}{ Weight } & \multirow{2}{*}{$\begin{array}{c}\text { Second } \\
\text { measurement } \\
\text { index }\end{array}$} & \multirow[b]{2}{*}{ Weight } & \multicolumn{3}{|c|}{ Measurement indicator value } \\
\hline & & & & Scheme 1 & Scheme 2 & Scheme 3 \\
\hline \multirow{2}{*}{$\begin{array}{l}\mathrm{R} \text { and } \mathrm{D} \\
\text { capability } \\
C_{1}\end{array}$} & \multirow[t]{2}{*}{0.27} & $\begin{array}{c}\text { R and D } \\
\text { funds investment } \\
\text { ratio } C_{11}\end{array}$ & 0.15 & 8.05 & 5.83 & 7.64 \\
\hline & & $\begin{array}{c}\text { R\&D } \\
\text { proportion of }\end{array}$ & 0.14 & 8.85 & 6.26 & 7.75 \\
\hline
\end{tabular}

This paper takes the technological innovation capability of three enterprises as samples and tests the algorithm and model. Measurement indicator values are acquired after survey, statistics, analysisand expert consultation. Results are shown in Table 2.

Table 2. Measurement Indicator Values of Enterprise Technological Innovation 


\begin{tabular}{|c|c|c|c|c|c|c|}
\hline & & $\begin{array}{c}\text { human resources } \\
C_{12}\end{array}$ & & & & \\
\hline & & $\begin{array}{l}\text { Number of } \\
\text { patent } C_{13}\end{array}$ & 0.13 & 15 & 22 & 18 \\
\hline & & $\begin{array}{r}\mathrm{R} \& \mathrm{D} \\
\text { cycle }^{C_{14}}\end{array}$ & 0.15 & $8.5-9.0$ & $7.2-8.0$ & 8.3-8.5 \\
\hline & & $\begin{array}{r}\text { Successful } \\
\text { rate of } \mathrm{R} \& \mathrm{D} C_{15}\end{array}$ & 0.15 & 6.72 & & 6.56 \\
\hline & & $\begin{array}{l}\text { Capability of } \\
\text { cooperation } C_{16}\end{array}$ & & & & 0.58 \\
\hline & & quality of $\mathrm{R}$ & & & $85^{0.80-0 .}$ & $80^{0.75-0 .}$ \\
\hline \multirow{5}{*}{$\begin{array}{l}\text { Implement } \\
\text { capability } \\
C_{2}\end{array}$} & & & $\theta$ & 0.72 & 0.81 & 0.65 \\
\hline & & Manufactu & 0.22 & $3.0-3$. & $2.6-2.8$ & $\begin{array}{ll} & 2.2-2 \\
.5 & \end{array}$ \\
\hline & & professionals $C_{23}$ & 0.19 & 0.21 & 0.25 & 0.18 \\
\hline & & $\begin{array}{c}\text { Overall } \\
\text { quality of } \\
\text { professionals } C_{24}\end{array}$ & 0.19 & $0^{0.75-0.8}$ & $80^{0.75-0 .}$ & $85^{0.80-0 .}$ \\
\hline & & $\begin{array}{c}\text { Training input } \\
\text { of } \\
\text { professionals } C_{25}\end{array}$ & 0.20 & 0.65 & 0.72 & 0.43 \\
\hline $\begin{array}{l}\text { Management } \\
\text { capability }{ }^{C_{3}}\end{array}$ & 0.18 & $\begin{array}{l}\text { Proportion of } \\
\text { management } \\
\text { team } C_{31}\end{array}$ & 0.16 & 0.11 & 0.08 & 0.15 \\
\hline
\end{tabular}




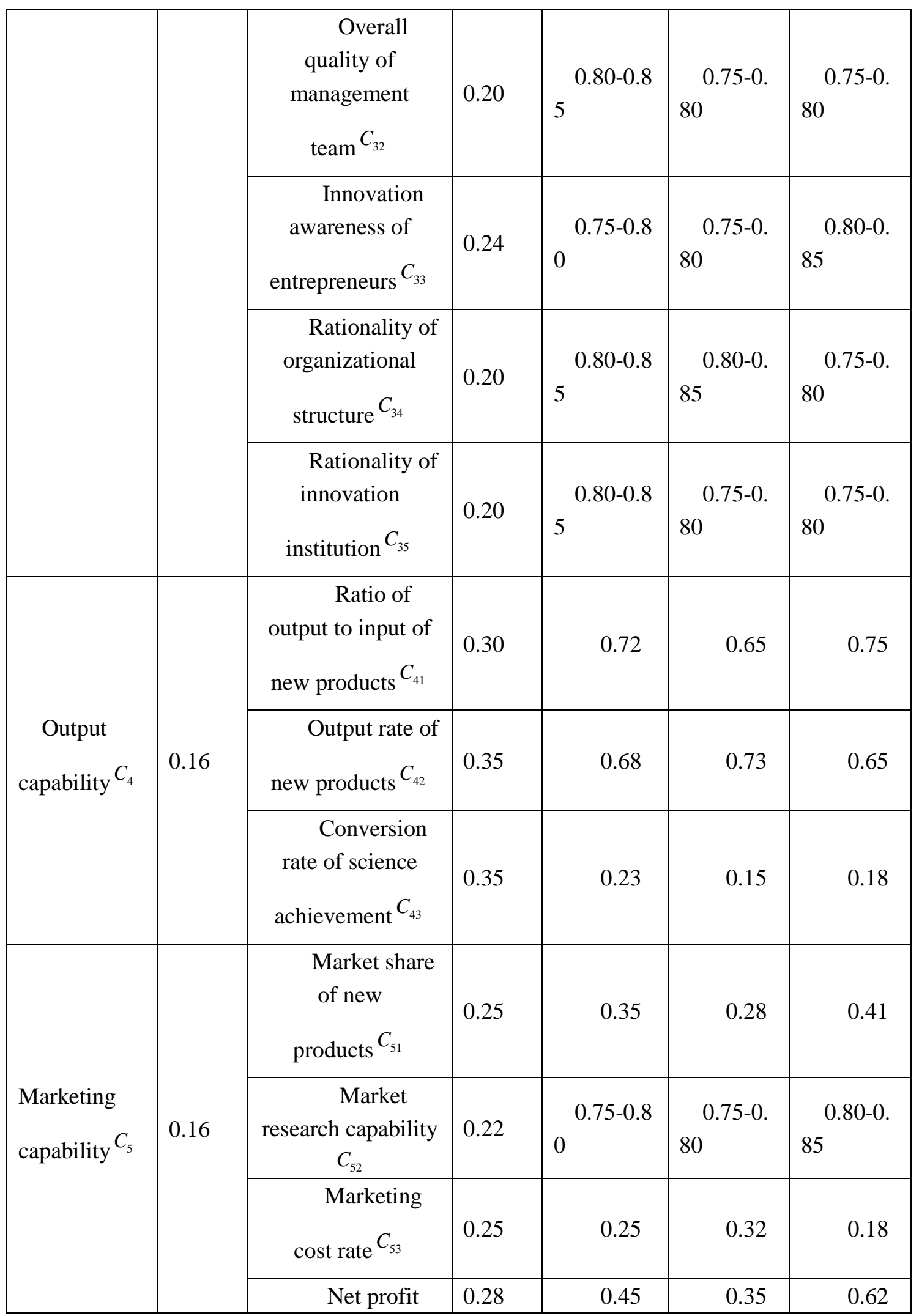




\begin{tabular}{|l|l|l|l|l|l|l|}
\hline & & $\operatorname{rate}^{C_{54}}$ & & & & \\
\hline
\end{tabular}

Standardize measurement indicators of different types as is shown in Table 3.

Table 3. Measurement Indicator Value of Enterprise Technological Innovation Capability

\begin{tabular}{|c|c|c|c|}
\hline \multirow{2}{*}{ Second measurement index } & \multicolumn{3}{|c|}{ Measurement indicator value } \\
\hline & Scheme 1 & Scheme 2 & Scheme 3 \\
\hline $\begin{array}{l}\mathrm{R} \text { and } \mathrm{D} \text { funds investment } \\
\qquad \text { ratio } C_{11}\end{array}$ & 1.000 & 0.724 & 0.949 \\
\hline $\begin{array}{l}\mathrm{R} \text { and } \mathrm{D} \text { proportion of } \\
\text { human resources } C_{12}\end{array}$ & & & 0.876 \\
\hline Number of patent $C_{13}$ & & 1.000 & 0.818 \\
\hline $\mathrm{R}$ and D cycle $C_{14}$ & & $\begin{array}{l}0.900-1.00 \\
0\end{array}$ & $\begin{array}{l}0.847-0.86 \\
7\end{array}$ \\
\hline $\begin{array}{r}\text { Successful ra } \\
\qquad{ }_{\mathrm{D}}^{C_{15}}\end{array}$ & & 0.868 & 0.976 \\
\hline & 0.903 & 1.000 & 0.806 \\
\hline Overall quality of $\mathrm{R}$ and $\mathrm{D}$ & $0.882-0.941$ & $\begin{array}{l}0.941-1.00 \\
0\end{array}$ & $\begin{array}{l}0.882-0.94 \\
1\end{array}$ \\
\hline Equipment level $C_{21}$ & 0.889 & 1.000 & 0.802 \\
\hline Manufacturin & $0.629-0.733$ & $\begin{array}{l}0.786-0.84 \\
\quad 6\end{array}$ & $\begin{array}{l}0.880-1.00 \\
0\end{array}$ \\
\hline $\begin{array}{r}\text { Proportion of } \\
\text { professionals } C_{23}\end{array}$ & 0.840 & 1.000 & 0.720 \\
\hline $\begin{array}{l}\text { Overall quality of } \\
\text { professionals } C_{24}\end{array}$ & $0.882-0.941$ & $\begin{array}{l}0.882-0.94 \\
\quad 1\end{array}$ & $\begin{array}{l}0.941-1.00 \\
\quad 0\end{array}$ \\
\hline Training input of & 0.903 & 1.000 & 0.597 \\
\hline
\end{tabular}




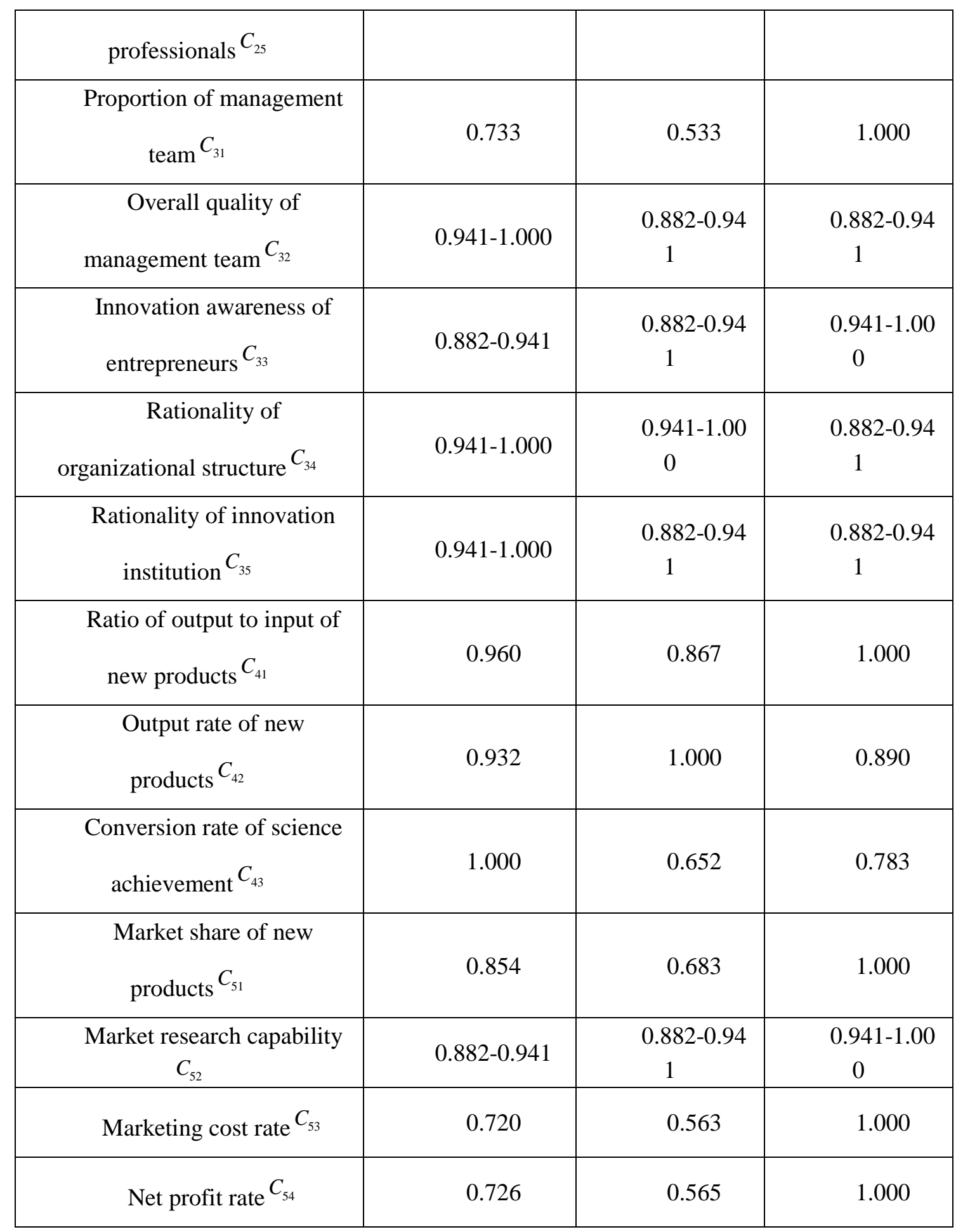

Euclidean distance is acquired as is shown in Table 4. 
Table 4. Euclidean Distance of Measurement Indicators

\begin{tabular}{|c|c|c|c|}
\hline \multirow{2}{*}{ Second measurement index } & \multicolumn{3}{|c|}{ Measurement indicator value } \\
\hline & Scheme 1 & Scheme 2 & Scheme 3 \\
\hline $\begin{array}{l}\mathrm{R} \text { and } \mathrm{D} \text { funds investment } \\
\qquad \text { ratio } C_{11}\end{array}$ & 0.000 & 0.276 & 0.051 \\
\hline $\begin{array}{l}\mathrm{R} \text { and } \mathrm{D} \text { proportion of } \\
\text { human resources } C_{12}\end{array}$ & 0.000 & 0.293 & \\
\hline Number of patent $C_{13}$ & 0.318 & & 0.182 \\
\hline $\mathrm{R}$ and D cycle $C_{14}$ & & & 0.101 \\
\hline $\begin{array}{l}\text { Successful rate of } \mathrm{R} \text { and } \\
\mathrm{D}^{C_{15}}\end{array}$ & & 0.132 & 0.024 \\
\hline $\begin{array}{l}\text { Capability of } \\
\text { cooperation } C_{16}\end{array}$ & & 0.000 & 0.194 \\
\hline Overall quality of $\mathrm{R}$ and & 0.059 & 0.000 & 0.059 \\
\hline 7 & 0.111 & 0.000 & 0.192 \\
\hline Manufacturin & 0.259 & 0.128 & 0.000 \\
\hline professionals $C_{23}$ & 0.160 & 0.000 & 0.280 \\
\hline $\begin{array}{l}\text { Overall quality of } \\
\text { professionals } C_{24}\end{array}$ & 0.059 & 0.059 & 0.000 \\
\hline $\begin{array}{l}\text { Training input of } \\
\text { professionals } C_{25}\end{array}$ & 0.097 & 0.000 & 0.403 \\
\hline $\begin{array}{l}\text { Proportion of management } \\
\text { team } C_{31}\end{array}$ & 0.267 & 0.467 & 0.000 \\
\hline Overall quality of & 0.000 & 0.059 & 0.059 \\
\hline
\end{tabular}




\begin{tabular}{|c|c|c|c|}
\hline management team $C_{32}$ & & & \\
\hline $\begin{array}{l}\text { Innovation awareness of } \\
\text { entrepreneurs } C_{33}\end{array}$ & 0.059 & 0.059 & 0.000 \\
\hline $\begin{array}{c}\text { Rationality of } \\
\text { organizational structure } C_{34}\end{array}$ & 0.000 & 0.000 & 0.059 \\
\hline $\begin{array}{l}\text { Rationality of innovation } \\
\text { institution } C_{35}\end{array}$ & 0.000 & 0.059 & 0.059 \\
\hline $\begin{array}{l}\text { Ratio of output to input of } \\
\text { new products } C_{41}\end{array}$ & & & 0.000 \\
\hline $\begin{array}{l}\text { Output rate of new } \\
\text { products } C_{42}\end{array}$ & & 0.000 & 0.110 \\
\hline $\begin{array}{l}\text { Conversion rate of } \\
\text { achievement } C_{43}\end{array}$ & & 0.348 & 0.217 \\
\hline 4 & 0.146 & 0.317 & 0.000 \\
\hline $\begin{array}{r}\text { Market resear } \\
C_{52}\end{array}$ & 0.059 & 0.059 & 0.000 \\
\hline Marketing cost tate $C_{53}$ & 0.280 & 0.437 & 0.000 \\
\hline Net piofit rate $C_{54}$ & 0.274 & 0.435 & 0.000 \\
\hline
\end{tabular}

Considering the weight of indicators, the information content sequence of three enterprises is: $I=(0.089,0.136,0.103)$. According to the optimal principle based on information axiom, enterprise 1 has the least information content under the measurement index system and the best technological innovation capability.

\section{Conclusion}

This paper proposes a measurement model of enterprise technological innovation capability while addressing the problems in the measurement analysis. This model realizes the standardization of measurement indicators of different types by establishing a 
measurement index system. it also calculate the Euclidean distance and proposes an improved calculation model of information content which makes it possible to measure the enterprise technological innovation capability. By practical test, the model is proved to be effective and feasible. It has a simple physical definition and calculation method with high accuracy and reliability. It can provide a good support for the computed-based intelligence technological innovation. It also serves as guidance to the development of enterprise technological innovation so as to increase the competitiveness of the enterprise.

\section{Acknowledgments}

This paper is supported by Scientific Research Foundation of Henan Province Education Department (No. 12A630078) and Decision Research Bidding Rrdject of Peoples Government of Henan Province (No. 2012B382).

\section{References}

[1] C. Prescott and L. H. Ensign, "Competing explanations for knowledgexchange: Technology sharing within the globally dispersed R\&D of the multinationar enterprise 5 ", Journal of High Technology Management Research, vol. 20, (2009), pp. 75-85.

[2] M. H. Bala Subrahmanya, "Pattern of technological infovations in small enterprises: comparative perspective of Bangalore (India) and Northeast England (UK) [J]", Technovation, vol. 25, no. 3, (2005), pp. 269-280.

[3] W. Dejin, "Research on technology innovation evaluation of enterprises [J]", Science and Technology Management Research, vol. 7,(2010), pp. 12-13+52.P

[4] T. Wei, J. Rifu and L. Meng, Research on technological innovation evaluation of enterprises [J]", Science and Technology Progressed and Policy, vol. 24, Mo. 5, (2007), pp. 195-200.

[5] Z. Yongyue, M. Zhiqiang and C. Yongqing, "Multi-level fuzzy comprehensive evaluation on enterprise's green technology innovation environment [J]", Science and Technology Progressed and Policy, vol. 27, no. 9, (2010), pp. 102-105

[6] K. Ke and W. Chunxiu, "Selection model of enterprise's investment project based on multi-level fuzzy evaluation method [J]", Industry Jechnology and Economy, vol. 27, no. 6, (2008), pp. 148-150.

[7] K. Cormican and D. O'Sullivan, "Auditing best practice for effective product innovation management [J]", Technovation, vol. 24, (2004), pp. 819-829.

[8] R. Adams, J. Bessant and R. Phelps, "Innovation management measurement: A review [J]", International Journal of Management Reviews, vol. 8, (2006), pp. 21-47.

[9] T. Yilin, "Research on evaluation index model of enterprise technological innovation [J]", Science and Technology Nanagement Research, vol. 7, (2009), pp. 173-175.

[10] M. Ogot, “Conceptual design using axiomatic design in a TRIZ framework [J]”, Procedia Engineering, vol. 9, (2011, pp. 736-744.

[11]D. Tang, G. Zhang and S. Dai, "Design as integration of axiomatic design and design structure matrix [J]", Robotics and Computer-Integrated Manufacturing, vol. 25, no. 3, (2009), pp. 610-619.

[12] W. Tichun, C. Bingfa and B. Liangfeng, "Multi-attribute Optimal Selection Model of Large-Scale Hydraulic Turbine Scheme Design Based on Information Axiom [J]", Journal of Nanjing University of Aeronautics and Astronautics, vol. 43, no. 6, (2011), pp. 822-826.

[13] A. M. Gonçalves-Coelho and A. J. F. Mourão, "Axiomatic design as support for decision-making in a design for manufacturing context: A case study [J]”, International Journal of Production Economics, (2007), vol. 109 , nos. 1-2, pp. 81-89. 